\title{
İdiyopatik Hipogonadotropik Hipogonadizme Neden Olan GNRH1 c.99delA Delesyonunun Klinik ve Genetik İncelemesi
}

\author{
Molecular Genetic and Clinical Investigation of the c.99delA Mutation in GNRH1 as a Cause of \\ Idiopathic Hypogonadotropic Hypogonadism
}

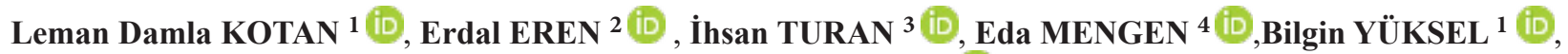 \\ A. Kemal TOPALOĞLU 5 (ib \\ ${ }^{1}$ Çukurova Üniversitesi, Tip Fakültesi, Çocuk Endokrinolojisi Bilim Dalı, Adana \\ ${ }^{2}$ Uludag Üniversitesi, Tıp Fakültesi, Çocuk Endokrinolojisi Bilim Dalı, Bursa \\ ${ }^{3}$ Şanlıurfa Ĕgitim ve Araştırma Hastanesi, Çocuk Endokrinoloji Kliniği, Şanlıurfa \\ ${ }^{4}$ Ankara Çocuk Sağlığı ve Hastalıkları Hematoloji Onkoloji Ĕgitim Araştırma Hastanesi, Çocuk Endokrinolojisi Kliniği, Ankara \\ ${ }^{5}$ Mississippi Üniversitesi, Pediatri Bölümü Nörobiyoloji ve Anatomi Bilimleri, Mississippi
}

Öz

"Gonadotropin Salgılatıcı Hormon 1" geni (Gonadotropin-releasing hormone 1, GNRH1), gonadotropin salgılatıcı hormon ailesinin üyesi olan bir preprohormonu kodlamaktadır ve İdiyopatik Hipogonadotropik Hipogonadizm'e (IHH) yol açan genler arasındadır. Bugüne kadar hastalıkla ilişkili olarak GNRH1'de oldukça sınırlı sayıda mutasyon bildirilmesine rağmen, homozigot c.99delA delesyonu farklı etnik kökenlere sahip IHH'li ailelerde tekrarlayan şekilde raporlanmıştır. Bu çalışmada, GNRH1 c.99delA mutasyonu taşıyan IHH tanılı üç bağımsız aileden toplam dört hastada ayrıntılı genetik ve klinik inceleme yapılması amaçlanmıştır. Bu ailelerdeki her üç indeks olgu da IHH'nin klinik olarak en ağır yansıması sayılan inmemiş testis/mikropenis ile başvurmuştur. GNRH1 mutasyonunun komşuluğundaki homozigot segmentlerin her üç ailede de farklı olması mutasyonun ortak bir atadan kalıtılmış (founder mutation) olmak yerine, mutasyona eğilimli bir bölge (mutational hotspot) nedeniyle oluşmuş olduğunu düşündürmektedir. GNRH1 homozigot mutasyonları IHH için halen nadir görülen nedenlerden biri olmasına rağmen hastalarda nedensel GNRH1 taraması yapılırken c.99delA mutasyonu öncelikli bakılması gereken noktaların başında gelmektedir.

Anahtar Kelimeler: GNRH1, idiyopatik hipogonadotropik hipogonadizm, delesyon, çerçeve kayması mutasyonu

\begin{abstract}
"Gonadotropin-releasing hormone 1" gene (GNRH1) encodes a preprohormone that is a member of the gonadotropin-releasing hormone family and is among the causal genes for the idiopathic hypogonadotropic hypogonadism (IHH) disease model. To date, although a very limited number of mutations have been reported in the GNRH1 associated with the disease, the homozygous c.99delA has been repeatedly reported in IHH families with different ethnic backgrounds. In this study, we aimed a detailed genetic and clinical investigation of four IHH patients from three independent families with GNRH1 c.99delA mutations. All three probands in these families presented with undescended testicles and/or micropenis, which is considered clinically the most severe manifestation of IHH. The fact that the homozygous regions flanking to the GNRH1 mutation are different in each of the three families suggest that the mutation is caused by a mutational hotspot rather than a founder mutation. Although GNRH1 homozygous mutations are still one of the rare causes of IHH, c.99delA mutation is a primary point to be noted when performing a causative GNRH1 screening.
\end{abstract}

Keywords: GNRH1, idiopathic hypogonadotropic hypogonadism, deletion, frameshift mutation 


\section{GİRISŞ}

Gonadotropin salg1latıcı hormon (Gonadotropin-releasing hormone, GnRH), hipotalamo-hipofizer-gonadal ekseni harekete geçirerek sekonder cinsiyet özelliklerinin ve üreme yeteneğinin gelişmesini, dolayısıyla pübertenin başlamasını sağlamaktadır. İdiyopatik Hipogonadotropik Hipogonadizm (IHH), anormal gonadotropin salgilanmasından kaynaklanan tam veya kısmi pubertal gelişim bozukluğuyla karakterize bir hastalıktır [1]. GNRH1 (Gonadotropin-releasing hormone 1), GnRH ailesinin üyesi olan bir preprohormonu kodlamaktadır [2]. İki farklı grubun 2009 yılında art arda GNRH1'deki homozigot çerçeve kayması mutasyonlarını IHH'li olgularda raporlaması sonucu, hastalıktan sorumlu genler listesine dahil olmuştur [3,4]. Ergenlik sürecindeki rolünün keşfinden bugüne kadar geçen sürede bu gende oldukça sınırlı sayıda mutasyon bildirilmiştir [5-7]. Ancak çalışmalar GNRH1 ve reseptörü olan GNRHR'nin IHH etiyolojisindeki en önemli aday genler olduğunu desteklemektedir [1,8]. IHH'li bir olguda GNRH1'deki homozigot c.99delA mutasyonu ilk olarak 2009 yilında Chan ve ark. tarafından bildirilmiştir [4]. Aynı pozisyondaki delesyon 2016 yilında merkezimizden Mengen ve ark. tarafından raporlanmıştır [7].

Bu çalışmada, GNRH1 genindeki nadir patojenik bulgulara rağmen, IHH hastalarında tekrarlayan şekilde bildirilen c.99delA delesyonunun ayrıntılı şekilde klinik ve genetik incelemesi ve ilgili mutasyon sıklığının nedenlerinin araştırılması amaçlanmıştır.

\section{YÖNTEM}

Çukurova Üniversitesi Tıp Fakültesi Çocuk Endokrinolojisi Polikliniğginde genetik çalışması yapılan, IHH tanılı ve etiyolojisinde GNRH1 (HGNC: 4419, NM_001083111.2) c. 99delA mutasyonu saptanan hastalar değerlendirmeye alınmıştır. c.99delA delesyonuna sahip olan hastalarda kalıtım paterninin belirlenebilmesi için aile içi segregasyon çalışması Sanger sekanslaması ile yapılmıştır. Değişimin in silico kontrolü için VarSome veritabanı kullanılmıştır [9]. Hasta bireylerin tüm eksom sekans verileri incelenerek mutasyonun bulunduğu homozigot bölgenin sınırları belirlenmiştir. Bu hastalarda bilinen diğer IHH genlerinde nedensel bir mutasyon tespit edilmemiştir. Bu çalışma Çukurova Üniversitesi Tıp Fakültesi Etik Kurulu tarafından onaylanmış (no: 81/2) ve çalışma hastalarından ve/veya velilerinden yazılı onam alınmıştır.

Aile 1: Üç yaşında sağ orşiopeksi operasyonu geçiren indeks olgu (II-4) 21 yaşındayken ergenlik bulgularının başlamaması yakınmasıyla Pediatrik endokrinoloji polikliniğine başvurdu. Arap kökenli olan anne ve babasının aralarında akraba olmadığı öğrenildi. Kemik yaşı, takvim yaşı ile uyumlu olan hastanın üç yıl önce HH tanısı ile insan koriyonik gonadotropini, follitropin alfa tedavisi aldığı öğrenildi. Testis hacmi bilateral $3 \mathrm{cc}$ olan hastanın tedavi sonrası Luteinleştirici Hormon (LH): 0,28 mIU/ml (0,4-7,0), Folikül Stimülan Hormon (FSH): 0,46 mIU/ml (2,60-11,00), Total Testosteron: $0,36 \mathrm{mg} / \mathrm{mL}(3,50-9,70)$ olarak saptand1. Olgunun 12 yaş 3 aylık erkek kardeşi (II-6) penis küçüklüğü şikayeti ile başvurdu. Kemik yaşı 11 yaş 6 ay ile uyumlu iken pubertal muayenesinde aksiller ve pubik k1llanma evre 1, testis hacimleri; sol 2-3 cc, sağ 1-2 cc olarak not edildi. Hormonal değerlendirmesinde LH: 0,34 mIU/ml, FSH: 0,32 mIU/ml, Total Testosteron: $0,13 \mathrm{ng} / \mathrm{mL}$ olması üzerine takibe alınan hastanın koku muayenesi normal, 13 yaş 6 aylıkken yapılan son değerlendirmesinde testisleri bilateral $2 \mathrm{cc}$ ve kemik yaşı takvim yaşı ile uyumluydu. Olgunun bazal LH: 0,60 $\mathrm{mIU} / \mathrm{ml}(0,20-4,90)$, FSH: 0,36 mIU/ml (1,80-3,20), Total Testosteron: $0,26 \mathrm{mg} / \mathrm{mL}(0,18-1,50)$, LHRH uyar1 testinde pik LH: 0,95 mIU/ml (>5) saptandı ve IHH tanısı aldı. Her iki olgunun hipofiz MR görüntülemesi normaldi.

Aile 2: Pediatrik endokrinoloji polikliniğine ilk kez 17 yaş 6 aylıkken testislerinin küçük olması yakınmasıyla başvuran indeks olgunun (II-1) özgeçmişinde sağ orşiopeksi operasyonu olduğu öğrenildi. Özgeçmişinde Türk kökenli anne ve babasının kuzen olduğu bildirilmişti. Pubertal değerlendirmesinde aksiller ve pubik kıllanma evre 1, testis hacimleri ise prepubertaldi. Koku muayenesi normal ve kemik yaşı takvim yaşı ile uyumlu olan hastanın bazal hormonal değerleri ve LHRH uyarı testi sonuçları IHH ile uyumluydu. Üç aylık testosteron tedavisi sonrası son muayenesinde testisleri bilateral $2 \mathrm{cc}$ ve LH: $<0,03 \mathrm{mIU} / \mathrm{ml}(0,4-$ 7,0), FSH: 0,1 mIU/ml (2,60-11,00), Total Testosteron: 0,72 $\mathrm{ng} / \mathrm{mL}(3,50-9,70)$ olarak not edildi. Yapılan LHRH uyarı testinde pik LH yanıtı $1 \mathrm{mIU} / \mathrm{ml}(>5)$ olan hastanın diğer hipofiz hormonları normal sinırlardaydı. Olgunun hipofiz MR görüntülemesi normaldi.

Aile 3: Onbeş yaş 9 aylık indeks olgu (II-1) ilk kez bir yaşında penis küçüklüğü ve bilateral inmemiş testis yakınması ile çocuk endokrinolojisi polikliniğine başvuran hasta iki yaşında orşiopeksi operasyonu geçirmiştir. Ebeveynlerinin Türk kökenli ve kuzen olup zamanında ergenlik yaşadıkları öğrenildi. Son muayenesinde testis hacimleri bilateral $1 \mathrm{ml}$ olan hastanın gerilmiş penis boyu $3.6 \mathrm{~cm}$, kemik yaşı ise 11 yaş ile uyumluydu. Hormonal değerlendirmesi LH: $0.1 \mathrm{mIU} / \mathrm{ml}(0.2-5,0)$, FSH: $0.2 \mathrm{mIU} / \mathrm{ml}(2,0-9,2)$ ve Total Testosteron $0,10 \mathrm{ng} / \mathrm{mL}(2,00-6,20)$ ile prepubertal olan hastanın koku muayenesi normaldi. Hasta IHH tanısıyla izlenmektedir. 


\section{BULGULAR}

Toplam, üç aileden dört hasta birey GNRH1 c.99delA homozigot mutasyonun (c.del99A/c.del99A) incelemesi için çalışmaya alınmıştır. $\mathrm{Bu}$ değişime göre, genin ilk eksonundaki kodlayan dizide 99. nükleotid pozisyonunda bulunan adeninin (A) kayb1 sonucu (c.99delA) baz diziliminde kayma meydana gelmiş ve 34. aminoasit olan glisin (Gly), glutamik aside (Glu) değişmiştir (p.Gly34Glufs) (Tablo 1a, 1b).

Tablo 1.a. GNRH1 33-42. aminoasit dizilimi, normal (wild-type) dizi. *koyu renk ile gösterilen baz, delesyon sonucu kayba uğramıştır

\begin{tabular}{|c|c|c|c|c|c|c|c|c|c|c|}
\hline Aminoasit no & 33 & 34 & 35 & 36 & 37 & 38 & 39 & 40 & 41 & 42 \\
\hline Triplet & GGA & GGA & AAG & AGA & GAT & GCC & GAA & AAT & TTG & ATT \\
\hline Aminoasit & Gly & Gly & Arg & Arg & Asp & Ala & Glu & Asn & Leu & Ile \\
\hline
\end{tabular}

Tablo 1.b. GNRH1 33-42. aminoasit dizilimi, mutant dizi

\begin{tabular}{|c|c|c|c|c|c|c|c|c|c|c|}
\hline Aminoasit no & 33 & 34 & 35 & 36 & 37 & 38 & 39 & 40 & 41 & 42 \\
\hline Triplet & GGG & GAA & AGA & GAG & ATG & CCG & AAA & ATT & TGA & - \\
\hline Aminoasit & Gly & Glu & Arg & Glu & Met & Pro & Lys & Ile & Ter & - \\
\hline
\end{tabular}

Sanger sekansı ve aile içi segregasyon çalışmaları ile birinci ailede ebeveynlerin delesyon için heterozigot olduğu (c.99delA/WT), genetik çalışması yapılabilen sağlıklı kardeşlerin ise her iki alelinde de mutasyon taşımadığı (wildtype, WT) (WT/WT) tespit edilmiştir. İkinci ailede kan örneğine ulaşılabilen ebeveynin heterozigot olduğu, üçüncü ailede ise ebeveynler ve sağl1klı kardeşin mutasyonu heterozigot (c.de199A/WT) taşıdığı belirlenmiştir (Şekil 1, 2). Hastaların eksom verilerinde delesyonun bulunduğu alan incelenmesinde, aile 1 (II-4) 21.5-35.4 Mb, aile 2 (II-1) 22.9$41.8 \mathrm{Mb}$ ve aile 3 (II-1) 12.4-52.7 Mb aralığında homozigot bölgeye sahip olduklarını belirlenmiş̧ir.

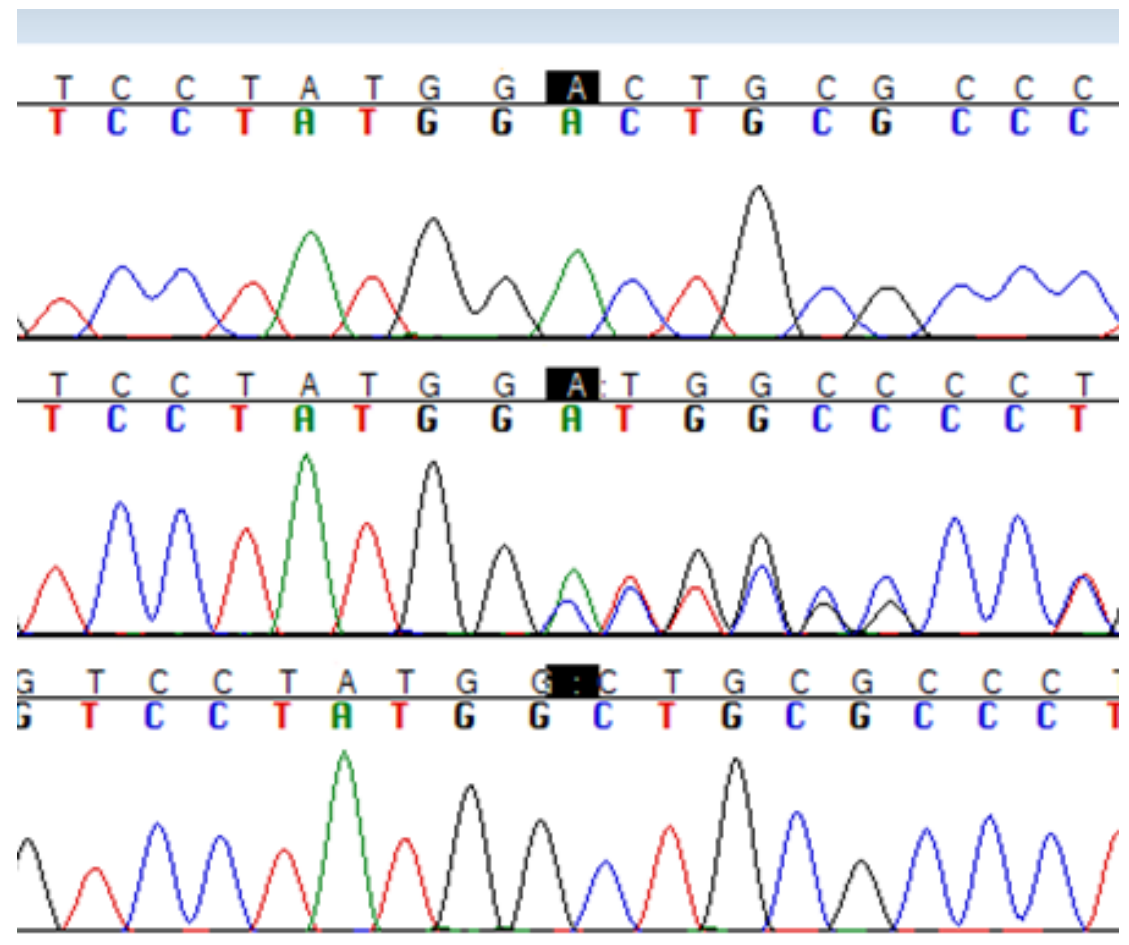

Şekil 1. GNRH1 c.de199A delesyonu sanger sekans dizilemesi. Üst sıra homozigot normal dizi (WT/WT), orta sira heterozigot mutant dizi (c.de199A/WT), alt sıra homozigot mutant dizi (c.de199A/c.de199A) gösterilmektedir 


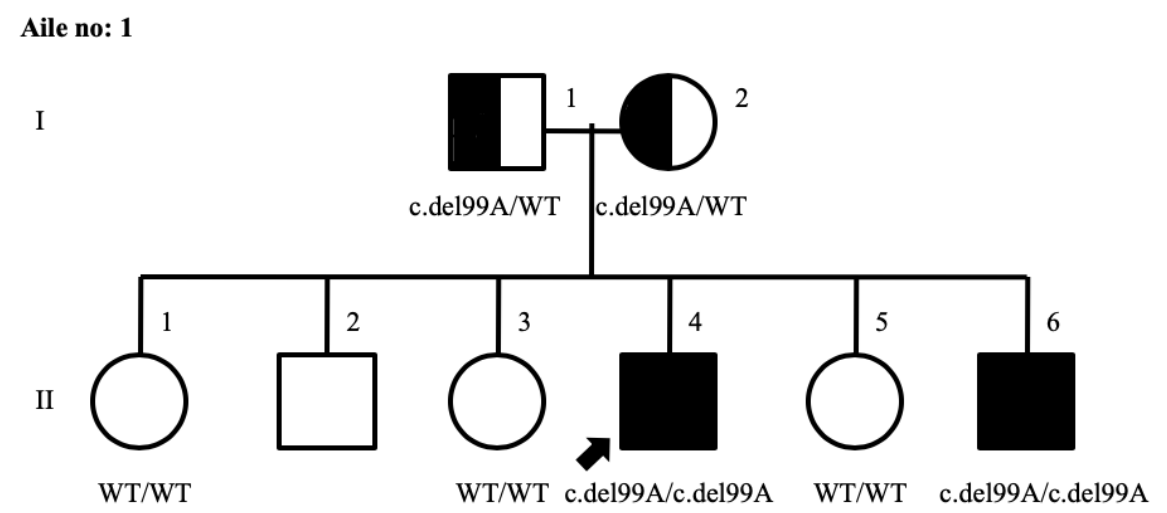

Aile no: 2

I

II

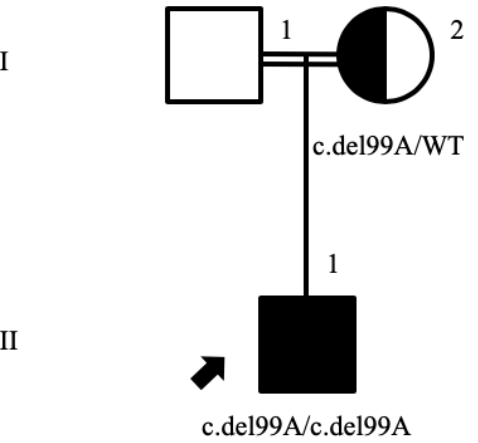

Aile no: 3

I

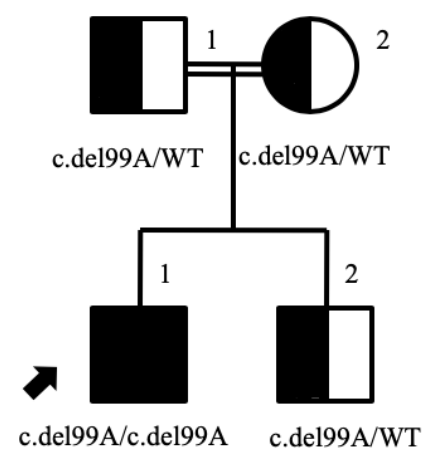

Şekil 2. c.del99A mutasyon segregasyonunun aile ağacı üzerinde gösterimi. Yuvarlak şekiller kadın, kareler erkeği temsil etmektedir. İçi tamamen taranmış şekiller delesyonu homozigot taşıyan bireyleri, yarım taranmış şekiller heterozigot taşıyan bireyleri, ok ise indeks olguyu göstermektedir. Çift çizgi ebeveynler arasında akrabalık olduğunu belirtmektedir

\section{TARTIŞMA}

$\mathrm{Bu}$ çalışmada GNRH1 geninde yineleyen bir şekilde gözlenen ve IHH kliniğine yol açan c.99delA çerçeve kayması mutasyonu klinik ve moleküler genetik özellikleri açısından incelenmiştir. Çerçeve kayması (frameshift, fs) mutasyonları, mRNA okunmasının standart kurallar dahilinde lokal değişiklikler ile yeniden dizilenmesidir. Bu gibi okuma çerçevesini değiştirebilen olaylar, oldukça nadir görülmesine karşın protein üretimini ciddi düzeyde etkileyebilecek güçtedir [10]. Bir aminoasidi temsil eden kodonun ikinci nükleotidinde başlayan protein translasyonları " +1 çerçeve kayması", üçüncü nükleotidinde başlayanlar ise "-1 çerçeve kayması" olarak tanımlanmaktadır [11]. Primatların mitokondriyal genomlarında yapılan taksonomik çalışmalarda, +1 çerçeve kayması mutasyonlarının - 1'e oranla daha fazla stop kodonu kombinasyonuna sahip olduğu bildirilmiştir
$[11,12]$. Bu durumdan ortaya çıan, +1 çerçeve kaymaları yoluyla doğal seleksiyonun optimize edildiği önermesi, +1 mutasyonlarının - 1'e göre daha patojenik sonuçları olduğunu düşündürmektedir [12]. IHH kliniğindeki hastalar1mizda tespit edilen c.99delA mutasyonu +1 siniflandırmasina girmektedir. Delesyonun sebep olduğu kayma sonucu yeniden düzenlenen okuma çerçevesinde, mutant bölgeden sekiz aminoasit sonra stop kodonunun (Termination, Ter) erken kodlanmasıyla dizi sonlanmıştır (p.Gly34GlufsTer8) (Tablo 1a,b). Çerçeve kayması mutasyonları sonrası oluşan yeni diziden sentezlenen peptidler çoğunlukla sitotoksik etkidedir $[11,13]$. Bu gibi prematür stop kodonu taşıyan mRNA'lar, zarar verici nitelikteki normal dışı protein üretiminin engellenebilmesi için nonsense-mediated decay (NMD) adlı mekanizma ile elimine edilmektedir [14]. c.99delA mutasyonunun VarSome veritabanı incelenmesi, ACMG/AMP 
2015 (The American College of Medical Genetics and Genomics and the Association for Molecular Pathology) kriterlerince hastalık yapıcı düzeyde PVS1 (pathogenic, very strong), PM2 (pathogenic, moderate), PP5 (pathogenic, supporting) ile skorlanmış ve delesyonun patojenik olduğu sonucuyla değerlendirilmiştir [15]. In silico programlarca çok yüksek ihtimalle NMD mekanizmasını aktive etmesi tahmin edilen c.99delA delesyonunu taşıyan hastalarımızda mutasyonunun bir sonucu olarak ilgili genden protein üretiminin olmaması ve GnRH aktivitesinin total kaybı beklenmektedir. Bu öngörüyle uyumlu olarak literatürdeki her iki c.del99A homozigot mutasyonlu hastada da komplet IHH mevcuttur $[4,7]$. Benzer şekilde daha sonra tanı koyulan hastalarımız da (Aile 1, II-4; Aile 2, II-1) IHH'nin en ağır klinik belirtisi sayılan inmemiş testis/mikropenis ile başvurmuştur. İnmemiş testis/mikropenis varlığı bu bireylerde hipotalamo-hipofizer-gonadal eksenin embriyonik ve fetal gelişimi sırasında GNRH1'in kodladığı GnRH'nın üretiminin ağır bir şekilde azalmış olduğunu telkin etmektedir.

Geçmiş çalışmalarda homozigot c.99delA mutasyonu Chan ve ark. tarafindan beyaz Avrupa kökenli bir ailede, Mengen ve ark. tarafindan ise Türk kökenli bir ailede (Aile 3, II-1) bildirilmiştir [4,7]. Bu çalışmadaki olgular dahil yayınlanmış bütün c.del99A delesyonlu hastalar dikkate alındığında tüm olguların Avrupa'dan bildirildiği gözlenmektedir. Bu durum, c.99delA delesyonunun atasal olarak ilk kez Avrupa'dan köken almış olabileceği ve ataların birinden doğup Avrupa' da yaşayan nesiller boyunca yayılan eski bir kurucu mutasyonu (founder mutation) temsil etmesinin olas1lığını düşündürmüştür [16]. Bu görüşün netleşmesi için haplotip analizi ve bağıntı analizi yöntemleri uygulanabilmektedir. Etkilenmiş bireyler arasında paylaşılan homozigot bölgelerin belirlenmesi esasına dayanan homozigosite haritalaması, otozomal resesif geçişli Mendel hastalıklarına neden olan genlerin tanımlanmasında kullanılan başarılı bir yöntemdir ve ebeveynlerden kalıtılan resesif hastalığa sahip bireylerde polimorfik belirteçlerin genomda taranması ile yapılmaktadır [17]. Tüm eksom sekanslaması tekniğini de kapsayan yeni nesil sekanslama verileri kullanılarak homozigotluk haritası oluşturulup, nedensel olabilecek değişiklikleri içeren bölgeler belirlenebilmektedir [18]. İlgili konumlanma, haritalaması yapılan üç hasta birey için de ortak homozigot bölge kapsamında bulunmaktadır. Ancak her üç hastanın da homozigot alan büyüklükleri, başlangıç ve bitim noktaları birbirinden farklıdır. Bu durumda c.99A delesyonunun ortak bir atadan kaynaklanması yerine aynı pozisyonda tekrarlayan bir mutasyon olabileceğini güçlü bir şekilde düşündürmektedir. Bu gibi belirli noktalara konsantre olmuş mutasyonlar, nükleotid sekansları boyunca mutasyona yatkın bölge (hotspot) olarak adlandırılan alanların varlığını işaret edebilmektedirler [19].

\section{SONUÇ}

GNRH1 homozigot mutasyonları IHH için halen nadir görülen nedenlerden biridir. Gendeki c.99delA delesyonunun IHH'ye sebep olduğu, çalışmamız ile birlikte toplamda üç farklı etnisitede değişik homozigot haplotip boyutlarıyla gösterilmiştir. Dolayısıyla IHH hastalarında nedensel GNRH1 taramas1 yapilırken c.99delA mutasyonu bir hotspot olarak öncelikli bakılması gereken noktaların başında gelmektedir. IHH'de aynı mutasyonların farklı klinik özelliklere neden olabileceği çeşitli kereler bildirilmişken, c. de199A mutasyonuna sahip hastaların hemen hemen aynı derecede ağır bir kliniğe sahip oldukları bu çalışmada gözlenmiştir. Bununla birlikte belirli bir populasyondaki kurucu mutasyonların ve/veya hotspotların tanımlanması, moleküler tanıya ve ilerleyen dönemlerde genetik danışmanlığa katkida bulunacaktır.

\section{Teşekkür}

Bu çalışma Çukurova Üniversitesi Bilimsel Araştırma Projeleri No: 11364 ve 4579 ile desteklenmiştir.

\section{KAYNAKLAR}

[1] Topaloglu, A.K. (2010). Update on the Genetics of Idiopathic Hypogonadotropic Hypogonadism, J Clin Res Pediatr Endocrinol, 9, 113-122.

[2] Chan, Y.M. (2011). A needle in a haystack: mutations in GNRH1 as a rare cause of isolated GnRH deficiency, Mol Cell Endocrinol, 346, 51-56.

[3] Bouligand, J., Ghervan, C., Tello, J.A., Brailly-Tabard, S., Salenave, S., Chanson, P., Lombes, M., Millar, R.P., Guiochon-Mantel, A., Young, J. (209). Isolated familial hypogonadotropic hypogonadism and a GNRH1 mutation, $N$ Engl $J$ Med, 360, 2742-2748.

[4] Chan, Y.M., de Guillebon, A., Lang-Muritano, M., Plummer, L., Cerrato, F., Tsiaras, S., Gaspert, A., Lavoie, H.B., Wu, C.H., Crowley, Jr. W.F., Amory, J.K., Pitteloud, N., Seminara, S.B. (2009). GNRH1 mutations in patients with idiopathic hypogonadotropic hypogonadism, Proc Natl Acad Sci US A, 106, 11703-11708.

[5] Maione, L., Albarel, F., Bouchard, P., Gallant, M., Flanagan, C.A., Bobe, R., Cohen-Tannoudji, J., Pivonello, R., Colao, A., Brue, T., Millar, R.P., Lombes, M., Young, J., Guiochon-Mantel, A., Bouligand, J. (2013). R31C GNRH1 mutation and congenital hypogonadotropic hypogonadism, PLoS One, 8, e69616. 
[6] Bouligand, J., Ghervan, C., Trabado, S., Brailly-Tabard, S., Guiochon-Mantel, A., Young, J. (2010). Genetics defects in GNRH1: a paradigm of hypothalamic congenital gonadotropin deficiency, Brain Res, 1364, 3-9.

[7] Mengen, E., Tunc, S., Kotan, L.D., Nalbantoglu, O., Demir, K., Gurbuz, F., Turan, I., Seker, G., Yuksel, B., Topaloglu, A.K. (2016). Complete Idiopathic Hypogonadotropic Hypogonadism due to Homozygous GNRH1 Mutations in the Mutational Hot Spots in the Region Encoding the Decapeptide, Horm Res Paediatr, 85, 107-111.

[8] Beranova, M., Oliveira, L.M., Bedecarrats, G.Y., Schipani, E., Vallejo, M., Ammini, A.C., Quintos, J.B., Hall, J.E., Martin, K.A., Hayes, J.F., Pitteloud, N., Kaiser, U.B., Crowley, Jr.W.F., Seminara, S.B. (2001). Prevalence, phenotypic spectrum, and modes of inheritance of gonadotropin-releasing hormone receptor mutations in idiopathic hypogonadotropic hypogonadism, J Clin Endocrinol Metab, 86, 1580-1588.

[9] Kopanos, C., Tsiolkas, V., Kouris, A., Chapple, C.E., Albarca Aguilera, M., Meyer, R., Massouras, A. (2018). VarSome: The Human Genomic Variant Search Engine, Bioinformatics, DOI 10.1093/bioinformatics/bty897.

[10] Gupta, A., Singh, T.R. SHIFT: server for hidden stops analysis in frame-shifted translation, BMC research notes, 6, 68.

[11] Seligmann, H., Pollock, D.D. (2004). The ambush hypothesis: hidden stop codons prevent off-frame gene reading, DNA Cell Biol, 23, 701-705.

[12] Singh, T.R. (2013). Mitochondrial Genomes and Frameshift Mutations: Hidden Stop Codons, their Functional Consequences and Disease Associations, Journal of Clinical \& Medical Genomics, 1.

[13] Singh, T.R., Pardasani, K.R. (2009). Ambush hypothesis revisited: Evidences for phylogenetic trends, Comput Biol Chem, 33, 239-244.
[14] Holbrook, J.A., Neu-Yilik, G., Hentze, M.W., Kulozik, A.E. (2004). Nonsense-mediated decay approaches the clinic, Nat Genet, 36, 801-808.

[15] Richards, S., Aziz, N., Bale, S., Bick, D., Das, S., Gastier-Foster, J., Grody, W.W., Hegde, M., Lyon, E. Spector, E., Voelkerding, K., Rehm, H.L., A.L.Q.A. Committee, (2015). Standards and guidelines for the interpretation of sequence variants: a joint consensus recommendation of the American College of Medical Genetics and Genomics and the Association for Molecular Pathology, Genetics in medicine : official journal of the American College of Medical Genetics, 17, 405-424.

[16] Charoute, H., Bakhchane, A., Benrahma, H., Romdhane, L., Gabi, K., Rouba, H., Fakiri, M., Abdelhak, S., Lenaers, G., Barakat, A. (2015). Mediterranean Founder Mutation Database (MFMD): Taking Advantage from Founder Mutations in Genetics Diagnosis, Genetic Diversity and Migration History of the Mediterranean Population, Hum Mutat, 36, E24412453.

[17] Botstein, D., Risch, N. (2003). Discovering genotypes underlying human phenotypes: past successes for mendelian disease, future approaches for complex disease, Nat Genet, 33 Suppl, 228-237.

[18] Wakeling, M.N., Laver, T.W., Wright, C.F., De Franco, E., Stals, K.L., Patch, A.M., Hattersley, A.T., Flanagan, S.E., Ellard, S., D.D.D. Study. (2019). Correction: Homozygosity mapping provides supporting evidence of pathogenicity in recessive Mendelian disease, Genetics in medicine : official journal of the American College of Medical Genetics, 21, 766.

[19] Rogozin, I.B., Pavlov, Y.I. (2003). Theoretical analysis of mutation hotspots and their DNA sequence context specificity, Mutat Res, 544, 65-85. 